\title{
CORRESPONDENCE
}

\author{
To THE EDITOR of Philosophy.
}

\section{THE ERRORS OF SIR ARTHUR EDDINGTON: A DEFENCE.}

SIR,

In No. 22 of this Journal Mr. Norman Campbell has published a series of objections in which he attacks Eddington's concept of modern physics. He performs his intention in such a clever and fair way that the difference is taken away out of a personal sphere and transformed into an objective matter. It is this turn to an objective matter which leads me to take part in this dispute-I myself being one of those who are endeavouring to form a philosophical interpretation of modern physics. I am far from agreeing with all particulars in Eddington's conception, but I must confess that his way of seeing modern theories seems to me to fit experiences so much better than Mr. Campbell's interpretation, that I want to give a defence of Eddington-a defence which indeed much more concerns modern physics than the interesting personality of that prominent English astronomer, who indeed is not attacked by Mr. Campbell, and needs no defence at all.

At the beginning of his criticism Mr. Campbell makes a distinction between physical theory and physical law. I cannot agree with him altogether here, as the difference between these two things seems to me only a matter of degree, and gradual transitions appear at all points. The two principles of Thermodynamics are called physical laws: Thermodynamics is called a physical theory. Classical thermodynamics, however, does not contain essentially more than these two laws, from which all other results are deduced. Usually speaking, a theory is a synopsis of several laws into a system; but as the number of propositions is no definite concept (as according to the way of speaking the same fact may be expressed by one or several propositions), there is no strict frontier between theory and law. Generally speaking, a theory is a system of laws which is not so well guaranteed as laws in a more narrow sense. But remembering that the most primitive laws already contain more than mere observation, it should be recognized that here only a difference of the degree of probability is concerned, and not a matter of principle.

More important than this question are the particular objections which Campbell addresses against Eddington. There are first the well-known illustrations of relativity by application of its concept of time to living beings. Campbell thinks such trains of thought impermissible, as their premises cannot be realized; living beings, for instance, cannot be moved with such velocities as are required in the imagined illustrations given. Therefore it would not be permissible to say what these people would see on such a journey. This argument is unconvincing. We very often make such generalizations, and they have a good sense, because they neglect only some non-essential factors and bring to a clear understanding the essential ones. If you want to describe the influence of a gravitational field on a human body, it is very instructive to relate the story of the man on the moon who emptily jumps like a giant; it is unessential and may be neglected, that men really cannot jump on the moon because there is no atmosphere. Besides, I must confess that $I$ do not think we are entitled to speak of an absolute impossibility. Why one day should not men jump on the moon, enveloped in a rubber-armour and with air-boxes on their back? And why should they not one day fly through the universe in space-vessels and reach velocities at which Einstein's time-dilatation becomes observable? I think we should leave this possibility to the engineers; for science there is a good sense in describing what these people would observe in their strange positions.

But I suppose that Mr. Campbell has other motives in attacking such imaginations. I suppose he is not convinced that living beings would share in the changes which, according to Einstein, atomic watches undergo. Perhaps Campbell does not think it permissible to say anything about this question before such experiments are 


\section{COR RESPON DEN CE}

performed. But it is to be remembered that it would be a vague hypothesis which assumed that physiological processes were governed by another time than the atomic processes on which they are based. For a fuller exposition I must refer to my book, Philosophie der Raum-Zeit-Lehrer; surely the much more substantiated hypothesis is that which believes physiological processes parallel to physical processes in their general qualities.

Corresponding answers are to be given to Campbell's objections against Eddington's conception of atomic proportions. Why is it not permissible to say that the interior of matter is comparable to the universal space, as it is indeed not more densely occupied with rigid nuclei than space with stars? Campbell says that "distance" in inter-atomic domains is something otherwise than "distance" between stars, because it is measured otherwise. But this is untenable. We may measure terrestrial distances in many ways without getting different sorts of distance. For instance, the distance between two mountains may be measured by placing rods end on end; or by aiming at the tops with a theodolite from the two ends of a base; or by an aeroplane-photograph which undergoes complicated optical transformations. But it is always the same sort of distance which is measured there. In this sense distances between stars and distances between atoms are of the same sort.

If Campbell further says that matter in the ordinary sense must be represented as solid as is customary, I think Eddington will not object to him. He will only add that this solidity is a rather crude concept, and ought to be represented in a more precise way as the collision of two clouds of dust in which only a few particles enter into the other cloud, and that in the whole repelling forces push the clouds away from each other. Why is it forbidden to say so? It is only maintained by this view that some macroscopic phenomena are better pictures of molecular processes than the usual conception of a continuous matter; and this fact, I think, cannot to-day be seriously denied.

Finally, as to Heisenberg's relation of indetermination, I must say that Mr. Campbell does not see the essential significance of this discovery. It is true that it was not possible for classical physics to determine both the position and velocity of an electron precisely; but the idea was held that improvement of determination to any chosen degree was in principle possible. Heisenberg says that this view is not true, and that there is an objective limit to improvement of exactness. It is unquestionable that our concept of causality receives a shock by this. In substantiating this statement I may refer to the fact that some time before the use of quantummechanics I gave a generalization of causality just in the same way and wrote about its philosophical consequences. Heisenberg's discovery appears to me, there fore, as the realization of a philosophical position which is to be drawn quite independently of all physical experiences. ${ }^{2}$

It may be admitted that several popular expositions of modern physics overstep the necessary bounds in figurative interpretation of physical results; but Eddington's expositions do not belong to these, at least in those points which Campbell puts forward. On the contrary, nothing seems to me so urgently required in the present philosophical situation as an unprejudiced interpretation of modern physics. The first necessity in pursuing this aim is a really earnest interpretation of the results of science, and the evaluation of their direct signification for the real world. It is not permissible to call modern physics a world of mathematical concepts which have a sort of mathematical life of their own, remote from the world of physical facts, which may, in the best instances, serve as reckoning aids for experimental physicists. On the contrary, we should know that our world really is structured otherwise than naive experience believes. As one of those who are earnest in this true interpretation of modern physics, I esteem Dr. Eddington.

\section{Yours faithfully,}

Hans Reichenbach, Professor of the Philosophy of Physics at the University of Berlin.

May I931.

I Berlin, 1928, de Gruyter, \$30.

- Die Kausalstruktur der Welt und der Unterschied von Vergangenheit und Zukunft, Ber. d. bayr. Akad. d. Wiss. math. phys. K1., München, 1925, S. 133. Cf. H. Reichenbach, Ziele und Wege der heutigen Naturphilosophie, Leipzig, 1931, F, Meiner, and some contributions to Erkenntnis, Annalen der Philosophie, Leipzig, F. Meiner. 